\title{
El valor en los discursos de destrucción bélica del patrimonio cultural
}

Francisco José Casado Pérez | Escuela Nacional de Conservación, Restauración y Museografía "Manuel del Castillo Negrete" (México)

URL de la contribución <www.iaph.es/revistaph/index.php/revistaph/article/view/4104>

A través del tiempo, la historia ha dejado entrever que las culturas humanas, por más distintas que digan ser, tienen ciertos rasgos que las asemejan, como es el caso de la destrucción del patrimonio cultural.

Tanto en el pasado como en el ahora, preguntarse el porqué de un acto tan radical como este tiene sus implicaciones en lo más profundo del hombre, como menciona Cassirer (2006: 25): "Se dice que es una criatura que en todo momento de su existencia tiene que examinar y hacer escrutinio de las condiciones de la misma. En ese escrutinio, en esta actitud respecto a la vida radica el valor de esta vida."

Dentro de dicha revisión, el concepto primordial a destacar son los valores, los cuales sintéticamente podrían verse como "...condiciones, tanto a nivel individual como social. Son razón y resultante del hombre, como de sus acciones, las cuales, pueden ser analizadas en relación a los parámetros establecidos en su propia temporalidad de origen y su evolución..." (CASADO, 2017: 43). De este modo la axiología, con la premisa de los juicios de valores, extiende una visión peculiar sobre el panorama de la destrucción bélica del patrimonio cultural.

Generalmente, este tipo de actos son calificados de salvajismo, crueldad o ignorancia por la sensibilidad cultural de víctimas y observadores, pero el clasificarlos de inhumanos o incultos son puntos de vista un tanto contradictorios. En primer lugar, me refiero a que son actos totalmente apoyados por la razón humana del grupo perpetrador $y$, en segundo, porque son ejercidos de manera consciente e intencional con base en las características tipológicas de los valores subdivididos en los tipos: objetivos, subjetivos, jerárquicos, polaridad y ope- ratividad, los mismos que configuran la identidad de cada cultura.

Por lo objetivo, la destrucción de la materialidad es un propósito práctico de conducción, donde el afectado pasa a un estado de duelo, un abatimiento anímico y moral debido a que el bien en cuestión es repositorio de los valores de la sociedad que, en la suma con otros similares, constituye una identidad cultural. Al momento de perder el mensaje simbólico -codificado por sus modelos expresivos- que funcionaba como referente de inspiración, al afectado ya no le quedan ideales motivacionales para continuar siendo ellos, permitiendo la imposición de los ideales y valores del atacante.

Lo subjetivo recae en cierto modo en el motivo, el cual puede dividirse entre distintos derroteros, dígase religión, economía, política, sociedad, cualesquiera, pero el punto neurálgico está en el poder y, por ende, el deseo. Ambos conceptos radican e influyen en la naturaleza y conducta humana por la necesidad natural de conocer y ordenar; al saber el contenido de algo y de qué manera le permitirá lograr un estado de estabilidad (nuevamente social, político, económico, psicológico, moral, entre otros) vale la pena buscar la forma de obtenerlo -incluso- por cualquier medio necesario.

En la imposición bélica, lo jerárquico es el elemento clave. Es un modo de encadenamiento que organiza la o las rutas para lograr los propósitos dictados en lo objetivo y subjetivo. Además es un refuerzo anímico que resalta la dualidad del poder: dominante y dominado; sin embargo, su magnitud y dirección dependerá de la habilidad de percepción de los valores por parte del atacante. 


\begin{abstract}
a debate Patrimonio, terrorismo y desastres naturales ¿Cómo prevenir y abordar los enormes daños al patrimonio cultural mundial?
\end{abstract}

| coordinan Francisco Javier López Morales, Francisco Vidargas

La polaridad en estos actos puede comprenderse a partir de dos puntos: la dialéctica existencialista y el principio de intercambio de Lockard. En el primero, cada acto irremediablemente tendrá una repercusión en los actores así como en el medio que le rodea, condicionando la búsqueda de estabilidad mencionada. Mientras que en la segunda idea, durante cualquier acto, hay un intercambio entre perpetrador y víctima, ambos se llevan consigo algo del otro, demostrando la inexistencia de lo prístino, sino que el hombre y la naturaleza está en constante construcción.

Finalmente la operatividad del valor es un punto crítico, debido a que su naturaleza es dinámica, como se dijo. Esto es porque su transmisión es paulatina y responde exclusivamente al hombre, supeditándose así a las necesidades y capacidades de este, así como sus oportunidades en el medio y los desarrollos que efectúe (materiales, filosóficos, morales, entre otros tantos). Esto último engloba todo lo anterior porque el cambio material será visto de manera subjetiva y por ende provocará una reorganización jerárquica a partir de una polarización, modificando la forma de percepción, por ejemplo, de lo novedoso a lo obsoleto, pero en este caso lo vital y lo superfluo.

En síntesis, la destrucción bélica del patrimonio ha sido el medio subversivo de la naturaleza de cierto grupo para satisfacer una necesidad o un deseo; no obstante, al ser una alusión del memento mori corre un riesgo al hacer presente la fragilidad humana dentro del patrimonio, la cual redirige la visión hacia el planteamiento sobre la necesidad de su protección, la cual, actualmente deberá ir en razón de una conciencia compleja, donde la amplia gama de identidades culturales existentes sea vista más como beneficio en lugar de amenaza; y planetaria, en consciencia de la realidad del ambiente y su relación crítica para las próximas generaciones, con lo cual ir construyendo de manera gradual y constante dichas premisas en relación con el paradigma axiológico del cambio perpetuo al que estamos irremediablemente sujetos.

\section{BIBLIOGRAFÍA}

- CASSIRER, E. (2016) [1944] Antropología filosófica: Introducción a una filosofía de la cultura, Eugenio Ímaz (trad.), $3^{\mathrm{a}}$ ed. México: Fondo de Cultura Económica (FCE), 2016 (Colección Popular, 41)

- CASAdo PÉREZ, F. J. (2017) Principios y criterios para la valorización y conservación de la vivienda modernista en la ciudad de México. Tesis de maestría en Conservación y Restauración de Bienes Culturales Inmuebles (tesis inédita)

- FRONDIZI, R. (1958) ¿Qué son los valores? Introducción a la axiología. México: FCE, 1958

- RUYER, R. (1969) [1952] Filosofía del valor. Agustín Ezcurdia Hijar (trad.). México: FCE, 1969

- TODOROV, T. (2002) Los dilemas de la memoria. Cátedra Latinoamericana Julio Cortázar [en línea] Universidad de Guadalajara, 2002 <http://www.jcortazar.udg.mx/sites/default/ files/TODOROV.pdf> [Consulta: 25/12/17] 